\title{
Assessment of neutrons from secondary cosmic rays at mountain altitudes - Geant4 simulations of environmental parameters including soil moisture and snow cover
}

\author{
Thomas Brall $^{1}$, Vladimir Mares ${ }^{1}$, Rolf Bütikofer ${ }^{2}$, and Werner Rühm ${ }^{1}$ \\ ${ }^{1}$ Institute of Radiation Medicine, Helmholtz Zentrum München, Ingolstädter Landstr. 1, 85764 Neuherberg, Germany \\ ${ }^{2}$ Space Research \& Planetary Sciences, University of Bern, Sidlerstr. 5, 3012 Bern, Switzerland
}

Correspondence: Thomas Brall (tbrall@web.de)

Received: 19 May 2021 - Discussion started: 15 June 2021

Revised: 26 August 2021 - Accepted: 30 August 2021 - Published: 11 October 2021

\begin{abstract}
Ground-based measurements of neutrons from secondary cosmic rays are affected by environmental parameters, particularly hydrogen content in soil. To investigate the impact of these parameters, in particular snow cover, Geant4 Monte Carlo simulations were carried out. In a previous study the model used for the Geant 4 Monte Carlo simulations was already validated by measurements performed with an extended-range Bonner sphere spectrometer (ERBSS) at Zugspitze, Germany, and at Jungfraujoch, Switzerland. In the present study a sensitivity analysis including different environmental parameters (i.e. slope of mountain, snow height, and soil moisture) and their influence on the flux of neutrons from secondary cosmic rays was performed with Geant4. The results are compared with ERBSS measurements performed in 2018 at the Environmental Research Station Schneefernerhaus located at the Zugspitze, Germany. It is shown that the slope of the Zugspitze mountain reduces the neutron flux from secondary cosmic rays between about $25 \%$ and $50 \%$ as compared to a horizontal surface, depending on neutron energy and snow cover. An increasing height of snow cover, simulated as snow water equivalent (SWE), reduces the total neutron flux exponentially down to a factor of about 2.5 as compared to soil without any snow cover, with a saturation for snow heights greater than 10 to $15 \mathrm{~cm} \mathrm{SWE}$, depending on neutron energy. Based on count rates measured with the individual spheres of the ERBSS, SWE values were deduced for the whole year 2018. Specifically, mean SWE values deduced for the winter months (January to March) are between 6.7 and $10.1 \mathrm{~cm}$ or more, while those for the summer months (July to September) are between 2.1 and $3.6 \mathrm{~cm}$.
\end{abstract}

Soil moisture of $5 \%$ water mass fraction in limestone leads to a decrease of the total neutron flux by about $35 \%$ compared to dry limestone. It is concluded that the measurement of neutrons from secondary cosmic radiation can be used to gain information on the height of snow cover and its seasonal changes, on soil moisture, and on local geometry such as mountain topography. Because the influence of such parameters on neutron flux from secondary cosmic rays depends on neutron energy, analysis of the whole neutron energy spectrum is beneficial.

\section{Introduction}

Neutrons from secondary cosmic rays (CRs) are always present at the Earth's surface as a component of natural radiation background. These neutrons are produced during cascade reactions in the Earth's atmosphere by primary CRs (mainly protons and helium nuclei). When reaching the atmosphere, the CR particles interact with the atoms of the air (basically oxygen and nitrogen atoms) and are continuously slowed down due to ionization. Additionally, they interact with the nuclei of these atoms, and new particles like protons, neutrons, and $\Pi$ and $K$ mesons are produced and characterized by a wide spectrum of energies extending up to several $\mathrm{GeV}$. Fast neutrons of energies below $10 \mathrm{MeV}$ may be evaporated from excited target nuclei. When reaching the ground, the transport of fast neutrons through soil is strongly influenced by the presence of hydrogen, which has the ability to rapidly moderate neutrons due to its large elastic scat- 
tering cross section and equal mass of projectile and target. Hydrogen at the land surface is mainly in the form of liquid and solid (ice, snow) water. This fact should be taken into account if spectral fluxes of neutrons from secondary CRs are measured on the ground level. It has been observed that snow accumulation in the environment of neutron detectors has a significant effect on the measured neutron flux energy distribution, because it influences the intensity of the ground albedo neutron flux (e.g. Tanskanen, 1968; Kodama, 1980; Eroshenko et al., 2008; Rühm et al., 2012). The influence of soil moisture on neutron flux measurements was already discussed by Hendrick and Edge (1966).

It has long been recognized that the measurement of albedo neutrons can be used to detect environmental hydrogen. For example, it has been proposed that albedo neutrons produced by cosmic radiation on the surface of Mars (or the Moon) could be used to detect the water content of Martian soil (e.g. Mitrofanov et al., 2004). Along these lines it has been also proposed to use neutrons from secondary cosmic radiation near the Earth's surface to detect soil moisture (Desilets et al., 2010; Zreda et al., 2012; Franz et al. , 2013; Andreasen et al., 2017; Köhli et al., 2021). Specifically, it was shown that detectors measuring thermal and/or epithermal neutrons close to the soil surface provide a signal that depends on soil moisture, within a radius on the order of about $100 \mathrm{~m}$ around the detector position (Desilets and Zreda, 2013; Köhli et al., 2015). A network of such neutron probes has already been installed for example in the US (Zreda et al., 2012) and the UK (Evans et al., 2016). Mobile systems were also proposed (Schrön et al., 2018). Detailed Monte Carlo (MC) calculations on neutron flux above ground were carried out by Sato and Niitab (e.g. 2006); Sato (e.g. 2015, 2016) with PHITS (Sato et al., 2018) and by Nesterenok (e.g. 2013) with Geant4 (Agostinelli, 2003).

In the beginning of the 20th century, after the discovery of the cosmic rays in 1912 by Victor Hess (Hess, 1912), inspired by the earlier work of Wulf and Gockel (e.g. Wulf, 1909, 1910; Gockel, 1911), mainly ionization chambers were used to measure the intensity of the cosmic rays. In the 1950s the neutron monitor (NM), developed by Simpson (Simpson et al., 1953), was considered the best groundbased detector capable of recording variations of primary CR intensity. Since the late 1950s, a global NM network (http://www.nmdb.eu, last access: 7 October 2021) was built to record long- and short-term changes of the CR intensity at ground level. NMs are sensitive to secondary particles produced in atmospheric cascades (mainly secondary neutrons) from primary CRs. They use the neutron-induced nuclear reactions $((n, 2 n),(n, 3 n))$ in lead included in their structure to multiply the number of secondary neutrons, which are then moderated to thermal energies and finally detected in the proportional counter tubes filled with ${ }^{10} \mathrm{BF}_{3}\left(\right.$ or $\left.{ }^{3} \mathrm{He}\right)$ gas through the detection of charged particles produced for example by the $\left.\left.{ }^{10} \mathrm{~B}(n, \alpha)\right)^{7} \mathrm{Li}\left(\text { or }{ }^{3} \mathrm{He}(n, p)\right)^{3} \mathrm{H}\right)$ reaction. This neutron multiplication technique increases significantly the counting rate of NMs and improves consequently the statistical accuracy of the neutron measurement. Because the number of produced secondary neutrons is almost independent on the energy of the incident neutron, a single NM cannot be used as a neutron spectrometer. If the neutron flux is required as a function of neutron energy in the range from thermal energies up to several $\mathrm{GeV}$, an extended-range Bonner sphere spectrometer (ERBSS) has to be used (Schraube et al., 1997; Mares and Schraube, 1998), which is based on the initial standard Bonner sphere spectrometer (BSS) (Bramblett et al., 1960).

The effect of hydrogen in snow on the flux spectra of secondary neutrons from CRs at ground level has recently been demonstrated by measurements at mountain altitude at the Environmental Research Station Schneefernerhaus (UFS) located at the Zugspitze mountain, Germany, and at sea level at the Koldewey station on Spitsbergen (Rühm et al., 2012). Specifically, it was shown that the flux of thermal and epithermal neutrons change by a factor of 2 between summer and winter season, at the UFS, while they change by about $50 \%$ at Spitsbergen. Seasonal changes in flux of MeV neutrons were roughly a factor of 2 smaller at both locations, while the flux of $100 \mathrm{MeV}$ neutrons did not change much at both locations. These changes were qualitatively attributed to the presence of snow during winter times and the absence of snow during summer times, but a quantitative evaluation of such an effect is still missing.

In this paper, detailed Monte Carlo (MC) simulations are described which allow quantification of the influence of environmental parameters such as snow cover and soil moisture on the energy spectrum of secondary CR neutrons. In a previous paper, first simulations were validated by means of experimental spectrometry using the ERBSS on the UFS and at Jungfraujoch, Switzerland, performed during winter and summer seasons, respectively (Brall et al., 2021). While there was overall agreement (within about $35 \%$ ) between measured and simulated neutron fluxes for energies above about $20 \mathrm{MeV}$, the comparison of measured and simulated neutron flux spectra below $20 \mathrm{MeV}$ was limited by the unknown hydrogen content in the environment close to the measurement locations. In the study described in the present paper, sensitivity analyses were carried out to investigate the influence of environmental parameters on simulated neutron flux spectra, with emphasis on the energy range between thermal and $\mathrm{MeV}$ energies. Specifically, it was investigated whether variations in height of snow cover and soil moisture in the environment of the measurement locations can improve the agreement between measurement and simulation at neutron energies below $20 \mathrm{MeV}$. 


\section{Materials and methods}

\subsection{Monte Carlo simulations}

\subsubsection{Overall procedure}

In a previous paper (Brall et al., 2021), MC simulations using the Geant 4 toolkit were used to assess the albedo neutron flux for two locations at mountain altitudes, one at the UFS on the Zugspitze mountain, Germany, the other at the High Altitude Research Station Jungfraujoch, Switzerland. While the station at the Jungfraujoch is located at an altitude of $3582 \mathrm{~m}$ a.s.l. on the top of a steep hill named "Sphinx", the station at the Zugspitze mountain is located on the southern slope of the Zugspitze mountain at an altitude of $2660 \mathrm{~m}$ a.s.l. The Geant4 simulations described in Brall et al. (2021) were done including three different physics lists, "QGSP_BERT_HP", "QGSP_BIC_HP", and "Shielding", which are all reference physics lists of the Geant4 toolkit (Geant4 Collaboration, 2017). For the present paper, these three physics lists were also used. Because the results of the simulations do not show any substantial differences between the physics lists, however, all results are presented and discussed here as obtained using the QGSP_BERT_HP (Bertini) physics list.

In order to reduce CPU computation time, the simulations were performed in a two-step process. In the first step, the primary CR particles were started at an altitude of $100 \mathrm{~km}$ and propagated down to a selected altitude. There the momenta of all secondary particles were scored in a pre-defined boundary surface. To avoid that secondary particles in the simulation are backscattered from the volume below the scoring region and then double counted in the scorer, a vacuum has been assumed instead of air below the scoring surface (for details please see Fig. 3 in Brall et al., 2021). In the second step, the particles scored were then used as source particles and further propagated to investigate the influence of local environmental parameters on neutron flux spectra at ground level. The number of primary particles was chosen such that the statistical uncertainties of the scored neutrons was less than $3 \%$ for the total neutron flux (and less than $6 \%$ per energy region of interest).

\subsubsection{Simulation geometries}

The geometry implemented in the Geant 4 toolkit to simulate neutrons from secondary $\mathrm{CR}$ at mountain altitudes is described in detail in Brall et al. (2021). Briefly, the primary radiation source includes protons and alpha particles from primary $\mathrm{CR}$ impinging on the top of the atmosphere (Burger et al., 2000; Usoskin et al., 2005). The parameters of the Earth's atmosphere and its elemental composition are implemented according to the US Standard Atmosphere 1976 (COESA 1976). For the present study, a horizontal flat soil disc was used to investigate the influence of environmental pa-

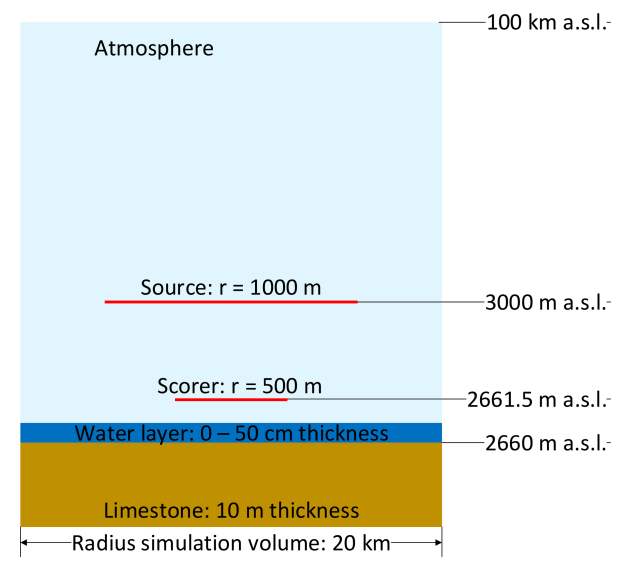

Figure 1. Geometry implemented in Geant 4 to evaluate the effect of water layers of different heights above the limestone.

rameters such as height of snow cover and soil moisture. A layer of limestone $\left(\mathrm{CaCO}_{3}\right)$ with a thickness of $10 \mathrm{~m}$ and a density of $2.7 \mathrm{~g} \mathrm{~cm}^{-3}$ was chosen as the soil material, because limestone is typical for the rock material in the investigated alpine region of the Zugspitze mountain.

\section{(a) Height of snow cover on dry limestone}

As a boundary surface in the first step of the simulation, a disc with a radius of $1000 \mathrm{~m}$ is chosen at an altitude of $2700 \mathrm{~m}$ as the source. The radius of the soil is $20 \mathrm{~km}$. The scorer is at an altitude of $2651.5 \mathrm{~m}$, i.e. $1.5 \mathrm{~m}$ above the soil level, and consists of a disc with a radius of $500 \mathrm{~m}$. On top of the soil, layers of water with various thickness are placed (1, $2,5,10,12.5,20$, and $50 \mathrm{~cm}$ snow water equivalent $-\mathrm{SWE}$ ) roughly simulating a snow layer with a thickness between 0 and $200 \mathrm{~cm}$ (Fig. 1). In all simulations, a snow density of $250 \mathrm{~kg} \mathrm{~m}^{-3}$ was assumed, which had been measured in the vicinity of the UFS (Hürkamp et al., 2019). Note that, typically, snow densities range from $50 \mathrm{~kg} \mathrm{~m}^{-3}$ (new snow) to $800 \mathrm{~kg} \mathrm{~m}^{-3}$ (very wet snow and firn) (Cuffey and Paterson, 2010).

\section{(b) Soil moisture}

In order to investigate the influence of soil moisture on neutron flux spectra of secondary CRs, water was added in the limestone in various mass fractions $(0 \%, 0.5 \%, 1 \%, 2 \%$, and $5 \%$ ). Such simulations were performed without any snow cover (i.e. $0 \mathrm{~cm} \mathrm{SWE}$ ) and with a snow cover (i.e. $5 \mathrm{~cm}$ SWE) (Fig. 1).

\subsection{Measurement of neutrons from secondary cosmic radiation}

At the Zugspitze mountain, Germany, the neutron flux spectra from secondary CRs was measured using an ERBSS. The spectrometer is described in detail in Schraube et al. (1997), 
Table 1. Ratio of neutron flux for horizontal geometry to that for slanted geometry (slant angle $45^{\circ}$ ), with $1 \sigma$ standard deviation of the Monte Carlo calculation.

\begin{tabular}{lcc}
\hline Snow water equivalent $(\mathrm{SWE})$ & $0 \mathrm{~cm}$ & $12.5 \mathrm{~cm}$ \\
\hline Total & $1.44 \pm 0.04$ & $1.34 \pm 0.05$ \\
Thermal $(E<0.4 \mathrm{eV})$ & $1.49 \pm 0.11$ & $1.36 \pm 0.08$ \\
Epithermal $(0.4 \mathrm{eV} \leq E<100 \mathrm{keV})$ & $1.52 \pm 0.06$ & $1.46 \pm 0.09$ \\
Evaporation $(100 \mathrm{keV} \leq E<20 \mathrm{MeV})$ & $1.40 \pm 0.05$ & $1.38 \pm 0.06$ \\
Cascade $(E \geq 20 \mathrm{MeV})$ & $1.25 \pm 0.05$ & $1.23 \pm 0.05$ \\
\hline
\end{tabular}

Mares and Schraube (1998), Leuthold et al. (2007), Rühm et al. (2008), Mares et al. (2020), Brall et al. (2020), and Brall et al. (2021). Briefly, $16{ }^{3} \mathrm{He}$ proportional counters were simultaneously used to detect thermalized neutrons. Thermalization was achieved by covering the counters with polyethylene (PE) spheres of various thicknesses (except for one proportional counter which was not covered by any PE, to detect environmental neutrons already thermalized). The response functions for the various counters were calculated for the energy range from $\mathrm{meV}$ up to $\mathrm{GeV}$ with $\mathrm{MC}$ simulations (Mares et al., 1991; Mares and Schraube, 1998). Count rates of the proportional counters together with their response functions were finally unfolded to obtain flux distributions as a function of neutron energy at the spectrometer positions.

\section{Results and discussion}

\subsection{Difference between horizontal and slanted soil}

In a previous paper (Brall et al., 2021), results of measurements of neutron flux spectra at the slope of the Zugspitze mountain are presented. In this work, simulations of the neutron flux spectra for the measurement location were done using a similar approach as was used for the present study. Consequently, the neutron flux spectra simulated in the previous paper for a slant angle of $45^{\circ}$ (Brall et al., 2021) could be compared with those obtained in the present study using horizontal ground. This was done for both dry limestone without snow cover and dry limestone with a cover of $50 \mathrm{~cm}$ of snow corresponding to $12.5 \mathrm{~cm} \mathrm{SWE}$.

Table 1 shows the ratio of the flux between horizontal geometry and slanted geometry for four energy regions (thermal: $E<0.4 \mathrm{eV}$; epithermal: $0.4 \mathrm{eV} \leq E<100 \mathrm{keV}$; evaporation: $100 \mathrm{keV} \leq E<20 \mathrm{MeV}$; cascade: $E \geq 20 \mathrm{MeV}$ ). Table 1 demonstrates that for the horizontal geometry, the flux of high-energy cascade neutrons $(E>=20 \mathrm{MeV})$ is higher by some $25 \%$ as compared to slanted soil, probably due to the fact that part of the $2 \pi$ geometry of the sky (i.e. upper half sphere) is shielded by the slanted surface. In contrast, for lower-energy neutrons, and in particular for thermal and epithermal neutrons, this effect increases by about $50 \%$. This can be explained by the mainly downward direction of cascade neutrons, while the lower-energy neutron flux

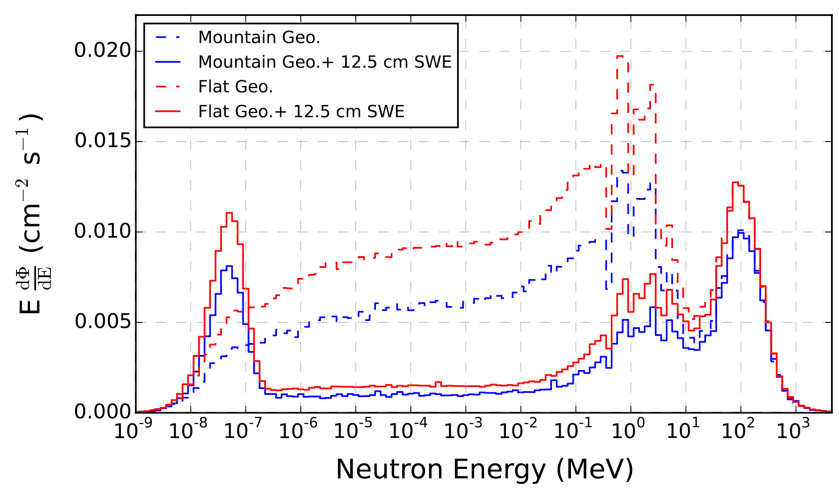

Figure 2. Neutron flux spectra for horizontal (red) and slanted soil (blue), with $50 \mathrm{~cm}$ snow layer (corresponding to $12.5 \mathrm{~cm} \mathrm{SWE}$ ) (solid line) and without snow (dashed line).

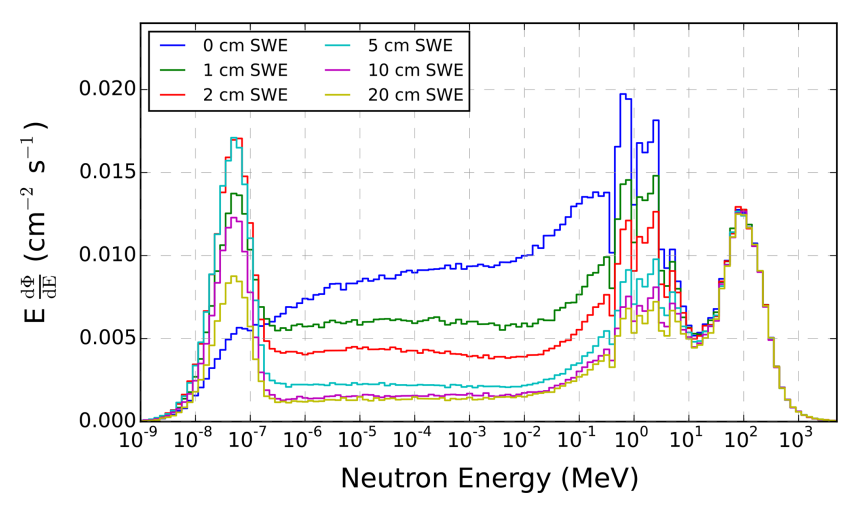

Figure 3. Neutron flux spectra simulated with water layers of different heights on ground.

is more isotropically distributed. This effect is roughly similar whether or not an additional water layer on top of the ground is considered. The corresponding neutron flux spectra are shown in Fig. 2.

\subsection{Influence of snow height on neutron flux spectra}

As already mentioned earlier, seasonal changes in the neutron flux spectra had been measured at the UFS (Rühm et al., 2012). In order to interpret the results of these measurements, the influence of snow height on the neutron flux spectrum was simulated in the horizontal geometry, and the results are shown in Fig. 3. In Fig. 4, the corresponding total flux and the flux for the four energy regions (thermal: $E<0.4 \mathrm{eV}$; epithermal: $0.4 \mathrm{eV} \leq E<100 \mathrm{keV}$; evaporation: $100 \mathrm{keV} \leq E<20 \mathrm{MeV}$; cascade: $E \geq 20 \mathrm{MeV}$ ) are shown as a function of the thickness of a water layer covering the ground.

For thermal neutrons, the flux increases with increasing thickness of the water layer up to a thickness of about $3 \mathrm{~cm}$, due to thermalization of higher-energy neutrons by the hydrogen in water. Beyond a thickness of about $3 \mathrm{~cm}$, the neutron flux decreases again, due to absorption of neutrons 


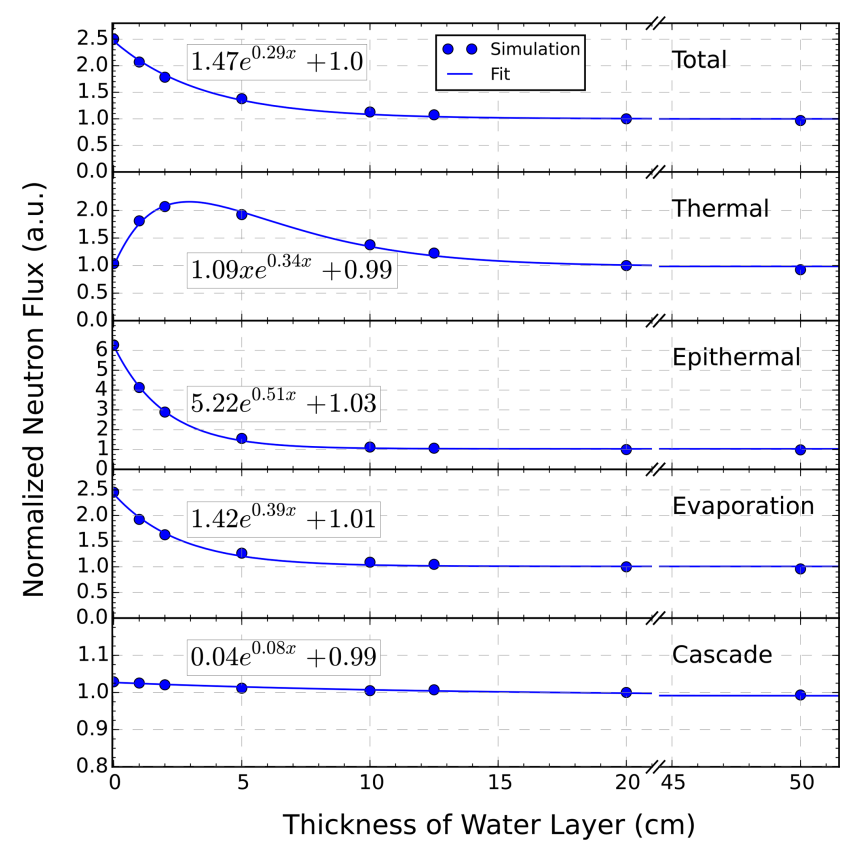

Figure 4. Neutron flux as a function of thickness of water layer on dry limestone soil at $2661.5 \mathrm{~m}$ a.s.1., for horizontal geometry and for different neutron energy ranges (thermal: $E<0.4 \mathrm{eV}$; epithermal: $0.4 \mathrm{eV} \leq E<100 \mathrm{keV}$; evaporation: $100 \mathrm{keV} \leq E<20 \mathrm{MeV}$; cascade: $E \geq 20 \mathrm{MeV}$; and total). Solid lines represent fits of the data points using a function of $a e^{-b x}+c$ for epithermal, evaporation, and cascade neutrons and $a x e^{-b x}+c$ for thermal neutrons.

backscattered from soil by the overlying water layer. In contrast, neutrons with higher-than-thermal energies do not show such an initial increase with increasing water thickness but decrease from the beginning almost exponentially with increasing water thickness, due to neutron moderation (Fig. 4). This decrease is most prominent for epithermal neutrons, followed by evaporation neutrons. In contrast, for high-energy cascade neutrons, this decrease is small and amounts only to about a few percent, probably because only few of these neutrons are backscattered by the soil and get absorbed or moderated by the overlying water layer. Interestingly, for any of the investigated energy regions, the neutron flux saturates at about $20 \mathrm{~cm}$ thickness of water layer (Figs. 3 and 4) and changes only little for greater water thickness. This means that the neutron energy spectrum does not change its shape substantially for water thicknesses greater than about $20 \mathrm{~cm}$ (corresponding to snow heights greater than about $60-80 \mathrm{~cm}$, depending on snow density).

Based on Fig. 5 the mean minimum and maximum values of the neutron flux in winter (January-March and December 2018) and summer (July-October 2018) were calculated, and, as a measure of the amplitude of the observed changes, the difference between maximum and minimum values was divided by 2 . For the four investigated energy regions, the results fit reasonably well with those reported in Rühm et al.

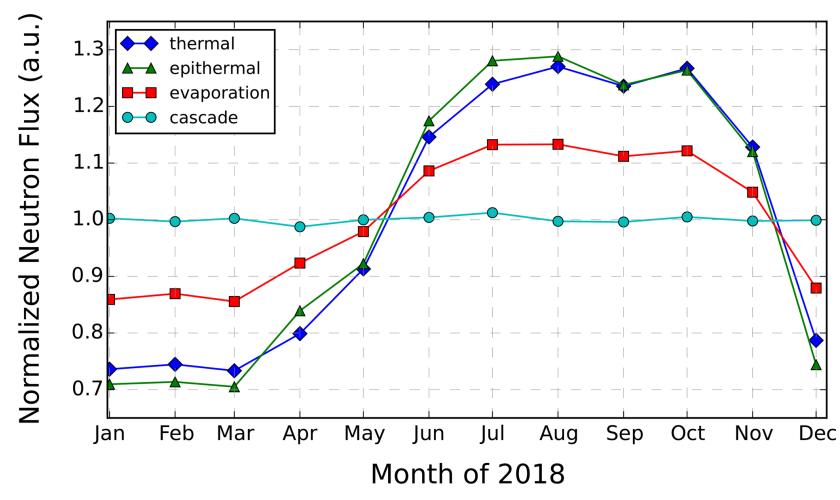

Figure 5. Monthly averaged neutron flux in 2018 at UFS Zugspitze, deduced from ERBSS neutron flux spectra for four energy regions (thermal: $E<0.4 \mathrm{eV}$; epithermal: $0.4 \mathrm{eV} \leq E<100 \mathrm{keV}$; evaporation: $100 \mathrm{keV} \leq E<20 \mathrm{MeV}$; cascade: $E \geq 20 \mathrm{MeV}$ ) normalized to annual mean flux.

(2012) where the corresponding amplitudes were obtained from a sinus function fitted over a period of 3 years (Table 2).

Based on the ratios between maxima and minima (1.67 \pm 0.03 for thermal, $1.77 \pm 0.03$ for epithermal, $1.30 \pm 0.01$ for evaporation neutrons), snow water equivalent values can be estimated for the summer months (July-October 2018) based on the fits shown in Fig. 4. As a result, for thermal neutrons SWE values of about 1 or $6 \mathrm{~cm}$ can be deduced. In contrast, for epithermal neutrons an unambiguous SWE value of about $4 \mathrm{~cm}$ and for cascade neutrons $6 \mathrm{~cm}$ can be deduced.

Because the flux of the cascade neutrons does not change much with season, an analysis similar to that for thermal, epithermal, and evaporation neutrons as given above was not considered reasonable for cascade neutrons.

The results obtained for thermal, epithermal, and evaporation neutrons suggest - if the neutron flux saturated during the winter months (for SWE values greater than about $15 \mathrm{~cm}$; see Fig. 4) - that during the summer months there was a mean snow water equivalent of about $4-6 \mathrm{~cm}$ in the vicinity of the ERBSS.

This analysis already suggests that it is possible to deduce the height of snow cover from analysis of the ERBSS neutron flux spectra. This encouraged us to perform a more detailed analysis, which is based on the pure count rates of the ERBSS proportional counters and which avoids the use of the unfolding process and associated uncertainties. This approach is described below.

\section{Interpretation in terms of thickness of water layer}

In order to validate these results with experimental data, measurements that had been made at the UFS, which is located at the slanted slope of the Zugspitze mountain at an altitude of $2660 \mathrm{~m}$ a.s.l., were used. Specifically, we used the count rates obtained by the ${ }^{3} \mathrm{He}$ proportional counters of the ERBSS for the comparison. 
Table 2. Normalized mean minimum (for January-March and December 2018) and maximum (for July-October 2018) neutron flux values (including standard deviation) taken from Fig. 5, the difference of these values divided by 2, and corresponding data taken from Rühm et al. (2012).

\begin{tabular}{lrrrrr}
\hline & Mean min & Mean max & Max/min & (Max - min)/2 & $\begin{array}{r}\text { Amplitude } \\
\text { (Rühm et al., 2012) }\end{array}$ \\
\hline Thermal & $0.75 \pm 0.02$ & $1.25 \pm 0.02$ & $1.67 \pm 0.03$ & $0.25 \pm 0.01$ & $0.27 \pm 0.02$ \\
Epithermal & $0.72 \pm 0.02$ & $1.27 \pm 0.02$ & $1.77 \pm 0.03$ & $0.28 \pm 0.01$ & $0.29 \pm 0.02$ \\
Evaporation & $0.87 \pm 0.01$ & $1.13 \pm 0.01$ & $1.30 \pm 0.010$ & $0.13 \pm 0.01$ & $0.14 \pm 0.01$ \\
Cascade & $1.0001 \pm 0.002$ & $1.003 \pm 0.007$ & $1.003 \pm 0.007$ & $0.001 \pm 0.004$ & $0.017 \pm 0.005$ \\
\hline
\end{tabular}

For this purpose, in a first step we used the simulated Geant4 neutron flux spectra obtained for the dry horizontal ground without the overlying water layer (see above). Because the measurements had been done on the slanted slope of the Zugspitze mountain (slant angle: $45^{\circ}$ ), the neutron flux spectra were corrected for the ratio of the simulated spectra of slanted to flat geometry (Table 1). In that way, a simulated neutron energy spectrum for the slanted slope was constructed. This spectrum was then folded with the response functions of the 18 proportional counters of the ERBSS to calculate the count rates of the ${ }^{3} \mathrm{He}$ proportional counters of the ERBSS. In other words, these count rates would be the count rates expected from an ERBSS based on the Geant4 simulations, for a slanted slope and ideal dry conditions i.e. no water in soil, no water on top of the soil, and no water in all the structures surrounding the ERBSS (e.g. building material and water pipes). This procedure was also applied to the Geant4 neutron flux spectra simulated in the present work for dry ground with overlying water layers with various thickness. That is, the count rates that are expected for an ERBSS located on a slanted slope including overlying water layers with various thickness were again calculated (by folding with the corresponding response functions). In a second step, these count rates were plotted as a function of water layer thickness, for each of the involved proportional counters, and fitted with the function $a e^{-b x}+c$ or $a x e^{-b x}+c$ for the bare detector, where $x$ is the thickness of the corresponding water layer. The result is shown in Fig. 6, and the corresponding fit parameters are listed in Table 3.

The daily ERBSS count rates actually measured in 2018 at UFS are shown in Fig. 7. These count rates were used to calculate, for every sphere and every day in 2018, the corresponding water thickness using the exponential function and the corresponding parameters from Table 3. Figure 8 shows these resulting water thicknesses for 2018 at UFS based on the count rates of the 16 ERBSS counters. Although the larger spheres and those including lead shells are less sensitive to low-energy (thermal, epithermal) neutrons than the smaller spheres, the overall annual count rates show qualitatively similar patterns, also taking into account the involved statistical uncertainties. Corresponding unfolded neutron flux spectra are shown in Fig. 9.

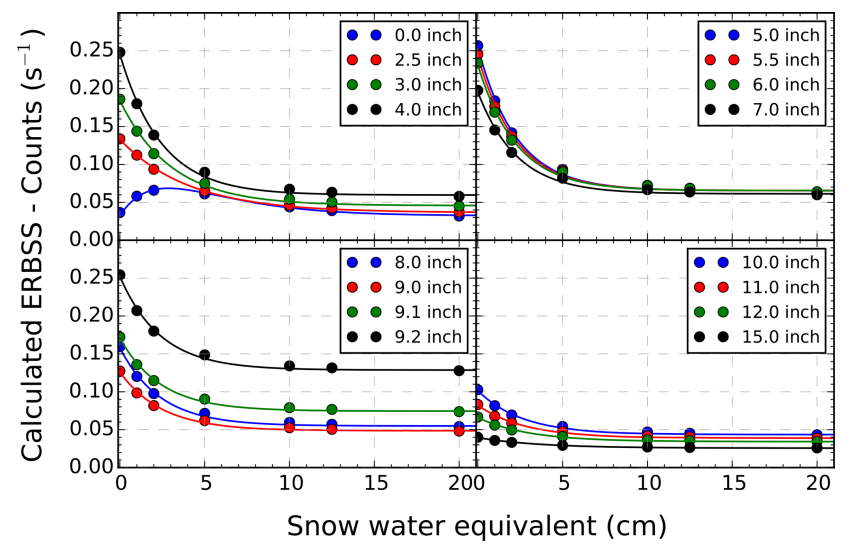

Figure 6. Count rates calculated for a solar modulation of $420 \mathrm{MV}$, for the ${ }^{3} \mathrm{He}$ proportional counters of the used extended-range Bonner sphere spectrometer (ERBSS), based on simulated Geant4 neutron flux spectra and response functions of the ERBSS. Solid lines are the fit of the data points to $a e^{-b x}+c$ or $a x e^{-b x}+c$ for the bare detector.

Table 3. Fit parameters of the fitted functions $\left(a e^{-b x}+c\right.$ or $a x e^{-b x}+c$ for the bare detector) shown as solid lines in Fig. 6 .

\begin{tabular}{lccr}
\hline Sphere & $a$ & $b$ & $c$ \\
\hline Bare & $0.034 \pm 0.003$ & $0.35 \pm 0.02$ & $0.032 \pm 0.001$ \\
2.5 in. & $0.097 \pm 0.001$ & $0.25 \pm 0.01$ & $0.036 \pm 0.001$ \\
3 in. & $0.139 \pm 0.003$ & $0.33 \pm 0.02$ & $0.046 \pm 0.002$ \\
4 in. & $0.186 \pm 0.005$ & $0.41 \pm 0.03$ & $0.060 \pm 0.002$ \\
5 in. & $0.189 \pm 0.005$ & $0.44 \pm 0.03$ & $0.065 \pm 0.002$ \\
5.5 in. & $0.177 \pm 0.005$ & $0.44 \pm 0.03$ & $0.066 \pm 0.002$ \\
6 in. & $0.166 \pm 0.005$ & $0.44 \pm 0.03$ & $0.066 \pm 0.002$ \\
7 in. & $0.135 \pm 0.004$ & $0.43 \pm 0.03$ & $0.061 \pm 0.002$ \\
8 in. & $0.103 \pm 0.003$ & $0.42 \pm 0.03$ & $0.055 \pm 0.001$ \\
9 in. & $0.077 \pm 0.002$ & $0.40 \pm 0.03$ & $0.049 \pm 0.001$ \\
9.1 in. & $0.096 \pm 0.003$ & $0.42 \pm 0.03$ & $0.075 \pm 0.001$ \\
9.2 in. & $0.124 \pm 0.004$ & $0.42 \pm 0.03$ & $0.129 \pm 0.002$ \\
10 in. & $0.058 \pm 0.002$ & $0.38 \pm 0.03$ & $0.044 \pm 0.001$ \\
11 in. & $0.043 \pm 0.002$ & $0.36 \pm 0.03$ & $0.039 \pm 0.001$ \\
12 in. & $0.032 \pm 0.001$ & $0.34 \pm 0.03$ & $0.034 \pm 0.001$ \\
15 in. & $0.014 \pm 0.001$ & $0.27 \pm 0.03$ & $0.0256 \pm 0.0003$ \\
\hline
\end{tabular}




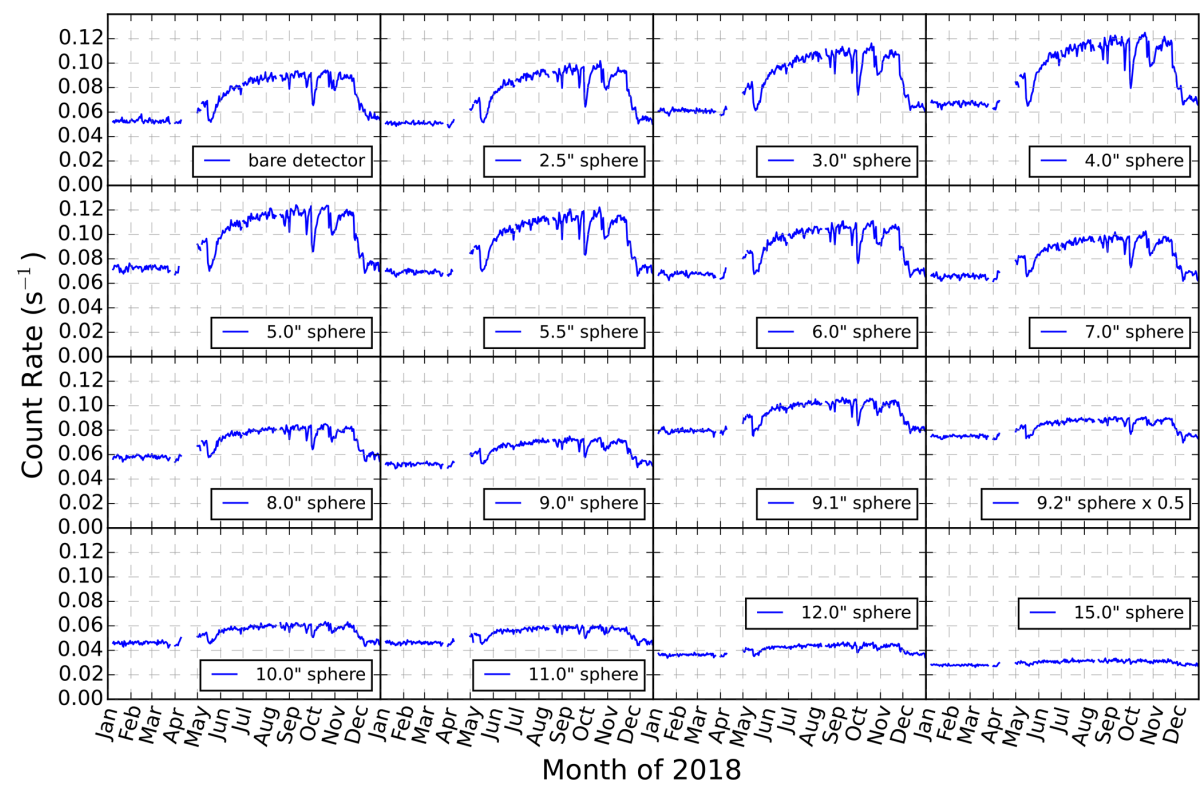

Figure 7. Measured daily count rates of the ERBSS proportional counters at UFS in 2018. Note that the count rates of the 9.2 in. sphere are divided by 2 to fit into the scale.

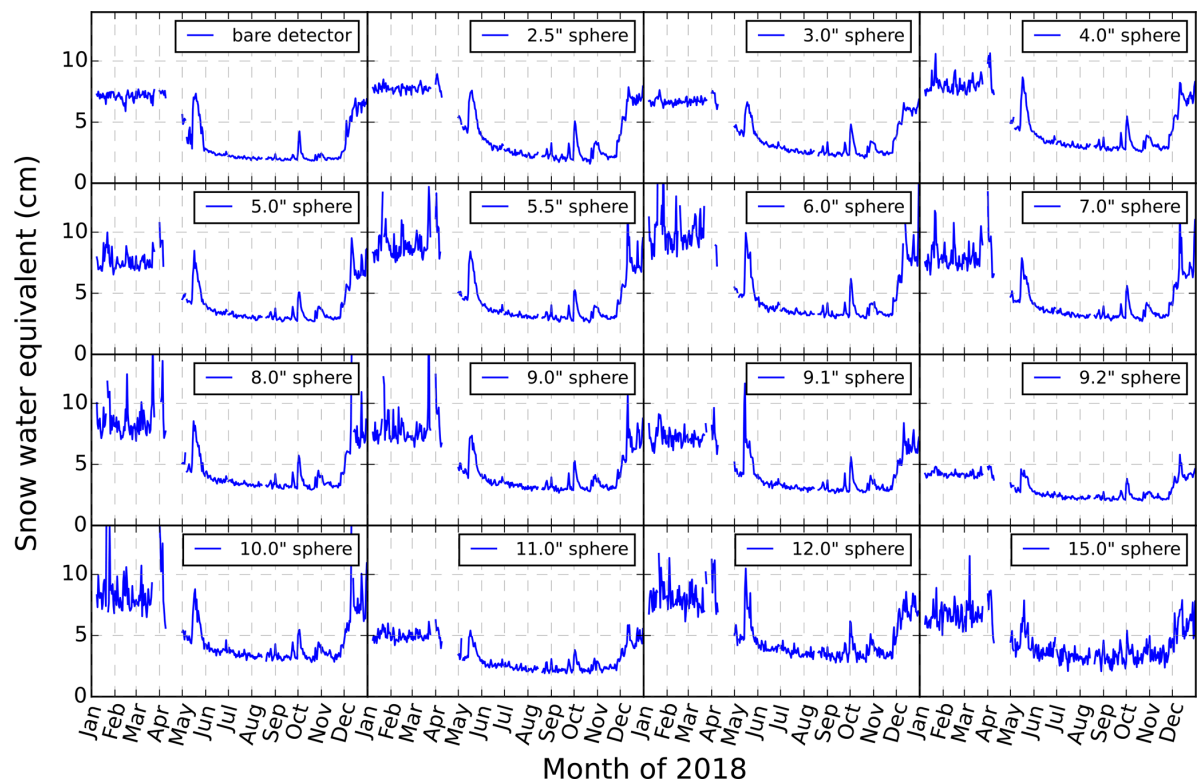

Figure 8. Daily calculated SWE in 2018 based on ERBSS count rates measured at UFS, the exponential fits shown in Fig. 6, and the corresponding fit parameters listed in Table 3. Thereby the QGSP_BERT_HP Geant4 physics lists were used to simulate the nuclear interactions.

From the daily water thickness values for the winter months (January until March) and the summer months (July until September), mean values were then calculated for each sphere (Table 4). For the winter months, all spheres give reasonable results between 6.7 and $10.1 \mathrm{~cm}$ SWE. The values from the 9.2 in. sphere (9in. PE sphere with lead shell) and the $11 \mathrm{in.} \mathrm{sphere} \mathrm{are} \mathrm{considerably} \mathrm{lower} \mathrm{than} \mathrm{the} \mathrm{values}$ computed for the other spheres. For the summer months, water thicknesses between 2.1 and $3.6 \mathrm{~cm}$ SWE were obtained.
Here, the thickness from the bare counter and the thicknesses from the $2.5 \mathrm{in}$., 9,2 in., and $11 \mathrm{in}$. spheres are somewhat lower than the other values. Because we had no detailed information on the type of snow present at the measurement times (e.g. density), all simulations were based on SWE values. We note, however, that Schattan et al. $(2017,2019)$ have shown that homogeneous and inhomogeneous snow distributions show a different influence on the neutron field. 


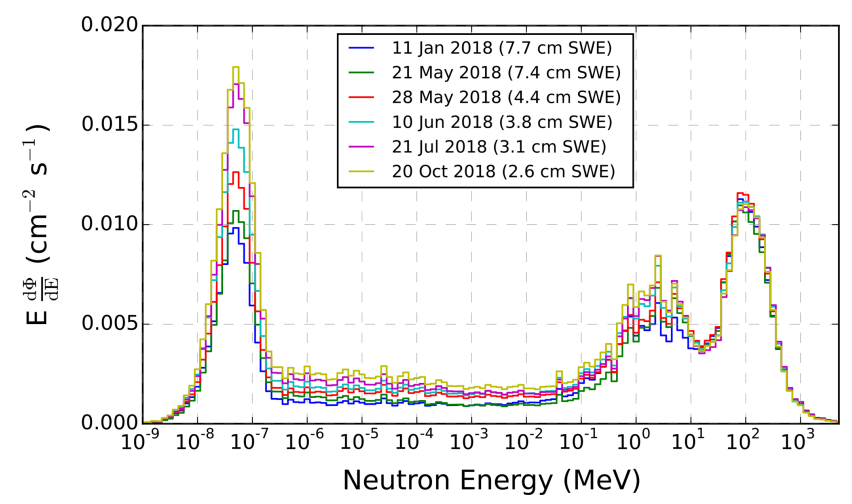

Figure 9. Unfolded ERBSS neutron flux spectra at UFS for selected dates in 2018; SWE calculated with the count rates of the 4 in. sphere.

Table 4. Snow water equivalent deduced from measured ERBSS count rates as calculated with the fit functions shown in Fig. 6 and the corresponding fit parameters listed in Table 3. Shown are the mean values from the daily values of Fig. 8, for winter times (January-March) and summer times (July-September) and their standard deviations.

\begin{tabular}{lrc}
\hline Sphere & $\begin{array}{r}\text { SWE }(\mathrm{cm}) \\
\text { (January-March) }\end{array}$ & $\begin{array}{c}\text { SWE }(\mathrm{cm}) \\
\text { (July-September) }\end{array}$ \\
\hline Bare & $7.11 \pm 0.34$ & $2.13 \pm 0.35$ \\
2.5 in. & $7.77 \pm 0.27$ & $2.43 \pm 0.56$ \\
3 in. & $6.71 \pm 0.27$ & $2.66 \pm 0.44$ \\
4 in. & $8.04 \pm 0.57$ & $3.13 \pm 0.46$ \\
5 in. & $7.60 \pm 0.66$ & $3.16 \pm 0.42$ \\
5.5 in. & $9.03 \pm 1.18$ & $3.21 \pm 0.45$ \\
6 in. & $10.07 \pm 1.83$ & $3.50 \pm 0.52$ \\
7 in. & $8.04 \pm 1.04$ & $3.31 \pm 0.47$ \\
8 in. & $8.58 \pm 1.30$ & $3.45 \pm 0.46$ \\
9 in. & $7.88 \pm 1.52$ & $3.25 \pm 0.43$ \\
9.1 in. & $7.24 \pm 0.63$ & $3.15 \pm 0.47$ \\
9.2 in. & $4.21 \pm 0.22$ & $2.34 \pm 0.30$ \\
10 in. & $8.36 \pm 1.52$ & $3.48 \pm 0.46$ \\
11 in. & $5.00 \pm 0.39$ & $2.36 \pm 0.35$ \\
12 in. & $8.13 \pm 1.06$ & $3.64 \pm 0.54$ \\
15 in. & $6.68 \pm 0.93$ & $3.28 \pm 0.57$ \\
\hline
\end{tabular}

For the summer months when there is no snow at the UFS, the measured values are between 2.7 and $3.6 \mathrm{~cm}$ SWE. This can be explained by the simplified assumptions used in the simulations. For example, complete dry limestone was assumed as a ground, and the building of the UFS research station was not considered. Thus, any contribution of the water content in the environment such as the typical $3 \%-10 \%$ water content of concrete, soil moisture, and any additional water content in the concrete floor around the detector housing could not be considered in the simulations, due to lack of information. Because an experimental verification of the simulated results would be a clue for testing the proposed approach, however, BSS measurements of neutron spectra would be desirable in an environment with a defined and well-known moisture in the relevant environmental compartments. For the winter months it can be seen from Fig. 7 that the count rates saturate and reach a minimum, corresponding to a maximum thickness of measurable SWE with ERBSS.

These results indicate that during the summer months a minimum in SWE is obtained. SWE values can also be measured during the snow melting period in spring and the beginning of the snow fall period in autumn. In this period a change in the ERBSS proportional counters is recognized and, thus, the deduced SWE thickness (Fig. 5). In contrast, the count rates of the ERBSS proportional counters saturate during winter times, and, thus, SWE thicknesses of more than 10-20 cm SWE cannot be determined based on ERBSS data (Figs. 5 and 7).

We note that the difference in SWE between winter and summer season is in most cases between 4 and $6 \mathrm{~cm}$; see Table 4 . This fits qualitatively to the results obtained when Fig. 4 and Table 2 are discussed (see above). It is also noted that the computations of the SWE based on measured ERBSS data implicitly include any moisture in the environment, for example the water content of the nearby concrete structure of the building and of the soil.

\subsection{Moisture of limestone}

The influence of soil moisture on the neutron flux spectra is shown in Fig. 10. For both geometries (i.e. pure soil and soil covered by a water layer with a thickness of $5 \mathrm{~cm}$ corresponding to a snow layer of about $20 \mathrm{~cm}$ ), water mass fractions $0 \%, 0.5 \%, 1 \%, 2 \%$, and $5 \%$ (which were used as examples) were implemented in the limestone. For the simulation without a water layer on the ground, the evaporation neutrons $(100 \mathrm{keV} \leq E<20 \mathrm{MeV})$ are moderated by the water in soil, and, for example, the flux of those neutrons decreases by about $25 \%$ with a water concentration of $5 \%$ in limestone, as compared to dry limestone. Similarly, the epithermal neutron flux $(0.4 \mathrm{eV} \leq E<100 \mathrm{keV})$ decreases by a factor of about 2 . In contrast, the thermal neutron flux $(E<0.4 \mathrm{eV})$ increases by about $20 \%$ when $5 \%$ moisture is added to the soil because the neutrons with higher energies are thermalized by the hydrogen. It may well be that if the soil moisture was increased further in the simulations, a decrease in thermal neutron flux might have been observed (similar to the behaviour of the thermal neutron flux as a function of SWE (Figs. 4 and 6)).

Sato and Niitab (2006) and Hubert et al. (2016) did similar calculations on the influence of soil moisture on the neutron flux, and their results are in line with those shown in Fig. 10.

Interestingly, when a $5 \mathrm{~cm}$ thick water layer is added on top of the limestone, soil moisture has practically no effect on the neutron flux spectra regardless of what water concentration is considered in the limestone for neutrons with energies greater than or equal to $0.4 \mathrm{eV}$ (epithermal, evaporation, cascade neutrons). It is only the thermal neutrons that are 

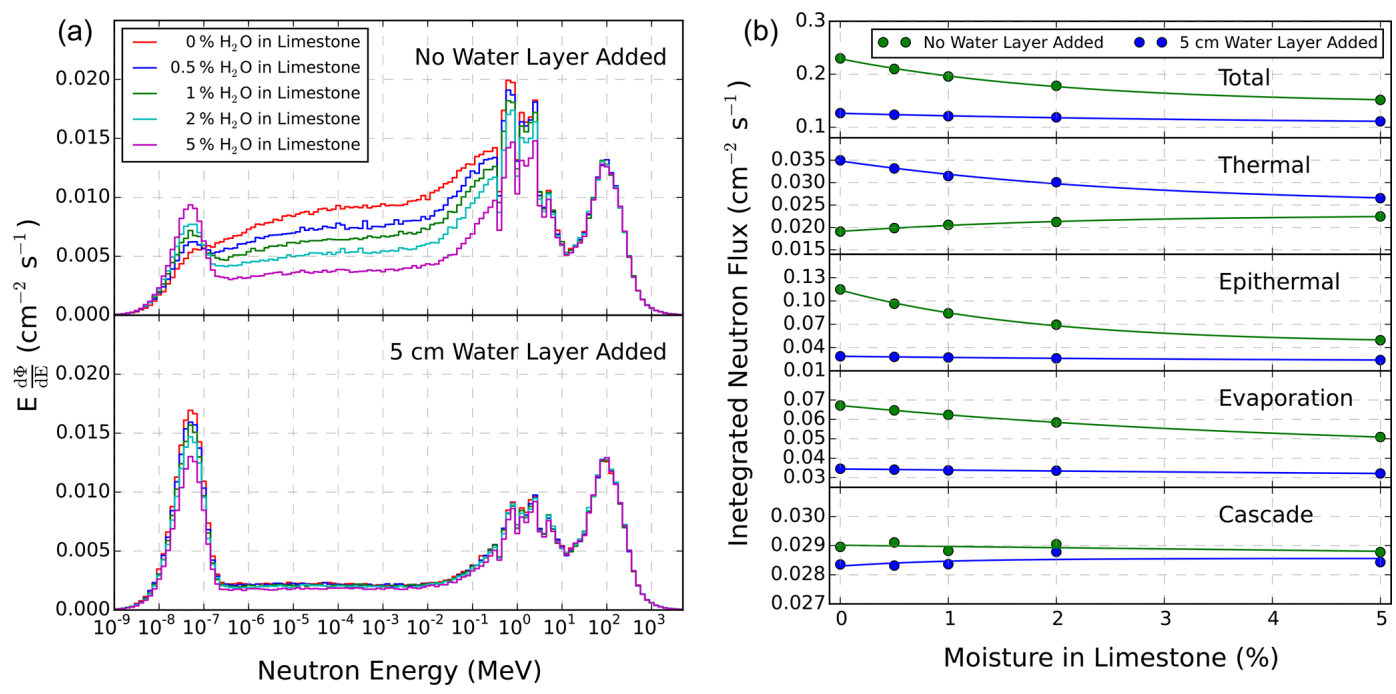

Figure 10. (a) Simulated neutron flux spectra with different moisture content in limestone $(0 \%, 0.5 \%, 1 \%, 2 \%$, and $5 \%)$ without a water layer on the ground (top) and with a $5 \mathrm{~cm}$ water layer on the ground (corresponding to a snow height of about $20 \mathrm{~cm})(\mathrm{bottom})$. (b) Neutron flux integrated over the whole energy range ("total") or integrated over the four considered neutron energy ranges (thermal: $E<0.4 \mathrm{eV}$; epithermal: $0.4 \mathrm{eV} \leq E<100 \mathrm{keV}$; evaporation: $100 \mathrm{keV} \leq E<20 \mathrm{MeV}$; cascade: $E \geq 20 \mathrm{MeV}$ ); solid lines represent fits of the data to $a e^{-b x}+c$.

slightly affected by the soil moisture, with the thermal neutron flux decreasing by about $25 \%$ for a soil moisture of $5 \%$ as compared to dry limestone.

In contrast, cascade neutrons $(E>20 \mathrm{MeV})$ are not affected at all by the moisture in the soil; also a $5 \mathrm{~cm}$ water layer has no effect on the cascade neutrons.

Note that other pools of hydrogen in the environment, such as air humidity or vegetation, were not investigated in the present study.

\section{Conclusions}

In this study a systematic analysis of the influence of environmental parameters on the neutron flux spectra from secondary CRs at mountain altitudes was performed. For this, Geant4 Monte Carlo calculations were made, and the influence of snow height and soil moisture on neutron flux energy distributions and range of albedo neutrons from soil were investigated.

As described in a previous publication, the Geant $4 \mathrm{MC}$ simulations were validated experimentally by means of ERBSS measurements of neutrons from secondary CR at UFS Zugspitze, Germany ( $2650 \mathrm{~m}$ a.s.1.) and in the astronomical cupola at the top of the Sphinx observatory on the Jungfraujoch, Switzerland (3585 m a.s.l.) (Brall et al., 2021).

The simulations described in the present paper were done for the UFS at an altitude of $2661.5 \mathrm{~m}$ a.s.l. on a limestone ground (which is typical for the Zugspitze region) assuming a horizontal surface. Soil moisture was varied from $0 \%$ to $5 \%$, and a SWE layer with a thickness between 0 and $50 \mathrm{~cm}$ was added (corresponding to snow heights up to about
$200 \mathrm{~cm}$ ), to investigate the influence of these parameters on the neutron flux spectra. The resulting simulated neutron flux spectra were corrected to account for the slanted area of the Zugspitze mountain as described in Brall et al. (2021) and folded with the ERBSS response functions to obtain the count rate for each ERBSS ${ }^{3} \mathrm{He}$ proportional counter. These count rates were then compared to those actually measured with the UFS ERBSS in 2018.

The influence of the snow depth on neutron flux shows that SWE affects the neutron flux - for energies below $20 \mathrm{MeV}$, strongly up to about $10 \mathrm{~cm} \mathrm{SWE}$, and for a thicker layer of water with more than $20 \mathrm{~cm} \mathrm{SWE}$, the effect of neutron absorption by hydrogen saturates, while no more change in the count rates can be recognized in the case of thicker water layers.

The SWE estimate from the measured count rates of the ERBSS at Schneefernerhaus, Zugspitze, provides consistent results for all spheres including the bare detector, except for the $11 \mathrm{in}$. and $9.2 \mathrm{in}$. spheres, which underestimate the SWE. The mean SWE values deduced for the winter months (January to March) were between 6.7 and $10.1 \mathrm{~cm}$, and they were between 2.1 and $3.6 \mathrm{~cm}$ for the summer months (July to September). For the summer months also the bare and $2.5 \mathrm{in}$. detectors provide somewhat lower values. Note that these results should be taken with care because considerable uncertainties remain.

Moisture in limestone also has a strong effect on the neutron flux for neutron energies below $20 \mathrm{MeV}$. However, the effect of moisture on neutron moderation and absorption only slightly affects thermal neutron flux when a layer of $5 \mathrm{~cm}$ of water on top of the limestone is present. 
We conclude that measurements of neutrons from secondary cosmic radiation with a ERBSS system are sensitive to hydrogen in the environment. This holds for the unfolded neutron flux spectrum and for the count rates obtained with the single ERBSS detectors. Specifically, information can be gained on heights of snow cover and its seasonal changes, on soil moisture, and on local geometry such as terrain gradients. The study performed demonstrates the importance of the measurement of neutron energies, because the influence of the investigated parameters strongly depends on neutron energy. More detailed and quantitative analyses would benefit from an optimized detector design with increased counting statistics and from detailed BSS measurements in an environment with known hydrogen content in the relevant environmental compartments.

Data availability. All experimental data from the ERBSS are show in Fig. 7. All data used for this work are presented in this paper.

Author contributions. All authors designed the project. TB performed the Monte Carlo simulations and analysed the data. TB and VM assessed the experimental data of the Bonner sphere spectrometer at Zugspitze mountain. All authors discussed and interpreted the results and wrote the manuscript.

Competing interests. The contact author has declared that neither they nor their co-authors have any competing interests.

Disclaimer. Publisher's note: Copernicus Publications remains neutral with regard to jurisdictional claims in published maps and institutional affiliations.

Acknowledgements. We would like to thank the staff of the UFS laboratory for their long-term support in the ERBSS measurements.

Financial support. This research has been supported by the Bayerisches Staatsministerium für Umwelt und Verbraucherschutz (grant no. 71_1d-U8729-2013/193-5).

Review statement. This paper was edited by Alexandre Langlois and reviewed by two anonymous referees.

\section{References}

Agostinelli, S.: Geant4 - a simulation toolkit, Nucl. Instrum. Meth. Phys. Res. A, 506, 250-303, https://doi.org/10.1016/S01689002(03)01368-8, 2003.

Andreasen, M., Jensen, K. H., Desilets, D., Franz, T. E., Zreda, M., Bogena, H. R., and Looms, M. C.: Status and perspectives on the cosmic-ray neutron method for soil moisture estimation and other environmental science applications, Vadose Zone J., 16, 4079, https://doi.org/10.2136/vzj2017.04.0086, 2017.

Brall, T., Dommert, M., Rühm, W., Trinkl, S., Wielunski, M., and Mares, V.: Monte Carlo simulation of the CERN-EU high energy Reference Field (CERF) facility, Radiat. Meas., 133, 106294, https://doi.org/10.1016/j.radmeas.2020.106294, 2020.

Brall, T., Mares, V., Bütikofer, R., and Rühm, W.: Assessment of secondary neutrons from galactic cosmic rays at mountain altitudes - Geant 4 simulations and ground-based measurements of neutron energy spectra, Radiat. Meas., 144, 106592, https://doi.org/10.1016/j.radmeas.2021.106592, 2021.

Bramblett, R. L., Ewing, R. I., and Bonner, T. W.: A new type of neutron spectrometer, Nucl. Instrum. Meth. Phys. Res., 9, 1-12, https://doi.org/10.1016/0029-554X(60)90043-4, 1960.

Burger, R., Potgieter, M., and Heber, B.: Rigidity dependence of cosmic ray proton latitudinal gradients measured by the Ulysses spacecraft: Implications for the diffusion tensor, J. Geophys. Res.-Space, 105, 27447-27455, https://doi.org/10.1029/2000JA000153, 2000.

Cuffey, K. M. and Paterson, W. S. B.: The physics of glaciers, 4th Edn., Academic Press, Amsterdam, 2010.

Desilets, D. and Zreda, M.: Footprint diameter for a cosmic-ray soil moisture probe: Theory and Monte Carlo simulations, Water Resour. Res., 49, 3566-3575, https://doi.org/10.1002/wrcr.20187, 2013.

Desilets, D., Zreda, M., and Ferré, T. P. A.: Nature's neutron probe: Land surface hydrology at an elusive scale with cosmic rays, Water Resour. Res., 46, W11505, https://doi.org/10.1029/2009WR008726, 2010.

Eroshenko, E., Velinov, P., Belov, A., Yanke, V., Pletnikov, E., Tassev, Y., and Mishev, A.: Relationships between cosmic ray neutron flux and rain flows, in: Proceedings of the 21st European Cosmic Ray Symposium, September 2008, Košice, Slovakia, 127-131, 2008.

Evans, J. G., Ward, H. C., Blake, J. R., Hewitt, E. J., Morrison, R., Fry, M., Ball, L. A., Doughty, L. C., Libre, J. W., Hitt, O. E., Rylett, D., Ellis, R. J., Warwick, A. C., Brooks, M., Parkes, M. A., Wright, G. M. H., Singer, A. C., Boorman, D. B., and Jenkins, A.: Soil water content in southern England derived from a cosmic-ray soil moisture observing system - COSMOS-UK, Hydrol. Process., 30, 4987-4999, https://doi.org/10.1002/hyp.10929, 2016.

Franz, T. E., Zreda, M., Rosolem, R., and Ferre, T. P. A.: A universal calibration function for determination of soil moisture with cosmic-ray neutrons, Hydrol. Earth Syst. Sci., 17, 453-460, https://doi.org/10.5194/hess-17-453-2013, 2013.

Geant4 Collaboration: Guide for physics lists, release 10.4, available at: http://geant4-userdoc.web.cern.ch/geant4-userdoc/ UsersGuides/PhysicsListGuide/BackupVersions/V10.4/html/ index.html (last access: 7 October 2021), 2017.

Gockel, A.: Messungen der durchdringenden Strahlung bei Ballonfahrten, Phys. Z., 12, 595-597, 1911. 
Hendrick, L. D. and Edge, R. D.: Cosmic-Ray Neutrons near the Earth, Phys. Rev., 145, 1023-1025, https://doi.org/10.1103/physrev.145.1023, 1966.

Hess, V.: über Beobachtungen der durchdringenden Strahlung bei sieben Freiballonfahrten, Phys. Z., 13, 1084-1091, 1912.

Hubert, G., Pazianotto, M. T., and Federico, C. A.: Modeling of ground albedo neutrons to investigate seasonal cosmic ray-induced neutron variations measured at highaltitude stations, J. Geophys. Res.-Space, 121, 12186-12201, https://doi.org/10.1002/2016JA023055, 2016.

Hürkamp, K., Zentner, N., Reckerth, A., Weishaupt, S., Wetzel, K. F., Tschiersch, J., and Stumpp, C.: Spatial and temporal variability of snow isotopic composition on Mt. Zugspitze, Bavarian Alps, Germany, J. Hydrol. Hydromech., 67, 49-58, https://doi.org/10.2478/johh-2018-0019, 2019.

Kodama, M.: Continuous monitoring of snow water equivalent using cosmic ray neutrons, Cold Reg. Sci. Technol., 3, 295-303, https://doi.org/10.1016/0165-232x(80)90036-1, 1980.

Köhli, M., Schrön, M., Zreda, M., Schmidt, U., Dietrich, P., and Zacharias, S.: Footprint characteristics revised for field-scale soil moisture monitoring with cosmic-ray neutrons, Water Resour. Res., 51, 5772-5790, https://doi.org/10.1002/2015WR017169, 2015.

Köhli, M., Weimar, J., Schrön, M., Baatz, R., and Schmidt. U.: Soil Moisture and Air Humidity Dependence of the AboveGround Cosmic-Ray Neutron Intensity, Front. Water, 2, 544847, https://doi.org/10.3389/frwa.2020.544847, 2021.

Leuthold, G., Mares, V., Rühm, W., Weitzenegger, E., and Paretzke, H.: Long-term measurements of cosmic ray neutrons by means of a Bonner spectrometer at mountain altitudes - first results, Rad. Prot. Dosim., 126, 506-511, https://doi.org/10.5194/tc2021-152, 2007.

Mares, V. and Schraube, H.: High energy neutron spectrometry with Bonner spheres, in: Proceedings, the IRPA Regional Symposium on Radiation Protection in Neighbouring Countries of Central Europe, September 1997, Prague, Czech Republic, 543547, 1998

Mares, V., Schraube, G., and Schraube, H.: Calculated neutron response of a Bonner sphere spectrometer with ${ }^{3} \mathrm{He}$ counter, Nucl. Instrum. Meth. A, 307, 398-412, https://doi.org/10.1016/01689002(91)90210-H, 1991.

Mares, V., Brall, T., Bütikofer, R., and Rühm, W.: Influence of environmental parameters on secondary cosmic ray neutrons at high-altitude research stations at Jungfraujoch, Switzerland, and Zugspitze, Germany, Rad. Phys. Chem., 168, 108557, https://doi.org/10.1016/j.radphyschem.2019.108557, 2020.

Mitrofanov, I. G., Litvak, M. L., Kozyrev, A. S., Sanin, A. B., Tret'yakov, V. I., Grin'kov, V. Y., Boynton, W. V., Shinohara, C., Hamara, D., and Saunders, R. S.: Soil Water Content on Mars as Estimated from Neutron Measurements by the HEND Instrument Onboard the 2001 Mars Odyssey Spacecraft, Solar Syst. Re., 38, 253-265, https://doi.org/10.1023/B:SOLS.0000037461.70809.45, 2004

Nesterenok, A.: Numerical calculations of cosmic ray cascade in the Earth's atmosphere - Results for nucleon spectra, Nucl. Instrum. Meth. Phys. B, 295, 99-106, https://doi.org/10.1016/j.nimb.2012.11.005, 2013.

Rühm, W., Mares, V., Pioch, C., Weitzenegger, E., and Paretzke, H.: Continuous measurements of secondary neutrons from cos- mic radiation at low atmospheric and low geomagnetic shielding by means of Bonner Sphere Spectrometers, in: Proceedings of the 21st European Cosmic Ray Symposium, ECRS XXI, Košice, Slovakia, 2008.

Rühm, W., Mares, V., Pioch, C., Weitzenegger, E., Vockenroth, R., and Paretzke, H. G.: Measurements of secondary neutrons from cosmic radiation with a Bonner sphere spectrometer at $79^{\circ} \mathrm{N}$, Radiat. Environ. Biophys., 48, 125-133, https://doi.org/10.1007/s00411-009-0219-y, 2009.

Rühm, W., Ackermann, U., Pioch, C., and Mares, V.: Spectral neutron flux oscillations of cosmic radiation on the Earth's surface, G. Geophys. Res., 117, A08309, https://doi.org/10.1029/2012JA017524, 2012.

Sato, T.: Analytical Model for Estimating Terrestrial Cosmic Ray Fluxes Nearly Anytime and Anywhere in the World: Extension of PARMA/EXPACS, PLoS One, 10, e0144679, https://doi.org/10.1371/journal.pone.0144679, 2015.

Sato, T.: Analytical Model for Estimating the Zenith Angle Dependence of Terrestrial Cosmic Ray Fluxes, PLoS One, 11, e0160390, https://doi.org/10.1371/journal.pone.0160390, 2016.

Sato, T. and Niitab, K.: Analytical Functions to Predict Cosmic-Ray Neutron Spectra in the Atmosphere, Radiat. Res., 166, 544-555, https://doi.org/10.1667/RR0610.1, 2006.

Sato, T., Iwamoto, Y., Hashimoto, S., Ogawa, T., Furuta, T., Abe, S., Kai, T., Tsai, P., Matsuda, N., Iwase, H., Shigyo, N., Sihver, L., and Niita, K.: Features of Particle and Heavy Ion Transport code System (PHITS) version 3.02, J. Nucl. Sci. Technol., 55, 684690, https://doi.org/10.1080/00223131.2017.1419890, 2018.

Schattan, P., Baroni, G., Oswald, S. E., Schober, J., Fey, C., Kormann, C., Huttenlau, M., and Achleitner, S.: Continuous monitoring of snowpack dynamics in alpine terrain by aboveground neutron sensing, Water Resour. Res., 53, 3615-3634, https://doi.org/10.1002/2016WR020234, 2017.

Schattan, P., Köhli, M., Schrön, M., Baroni, G., and Oswald, S. E.: Sensing area-average snow water equivalent with cosmic-ray neutrons: The influence of fractional snow cover, Water Resour. Res., 55, 10796-10812, https://doi.org/10.1029/2019WR025647, 2019.

Schraube, H., Jakes, J., Sannikov, A. V., Weitzenegger, E., Roesler, S., and Heinrich, W.: The Cosmic Ray Induced Neutron Spectrum at the Summit of the Zugspitze $(2963 \mathrm{~m})$, Radiat. Prot. Dosim., 70, 405-408, 1997.

Schrön, M., Rosolem, R., Köhli, M., Piussi, L., Schröter, I., Iwema, J., Kögler, S., Oswald, S. E., Wollschläger, U., Samaniego, L., Dietrich, P., and Zacharias, S.: Cosmic-ray neutron rover surveys of field soil moisture and the influence of roads, Water Resour. Res., 54, 6441-6459, https://doi.org/10.1029/2017WR021719, 2018.

Simpson, J. A., Fonger, W., and Treiman, S. B.: Cosmic Radiation Intensity-Time Variations and Their Origin. I. Neutron Intensity Variation Method and Meteorological Factors, Phys. Rev., 90, 934-950, https://doi.org/10.1103/physrev.90.934, 1953.

Tanskanen, P.: Influence of Snow on Neutron Monitor Intensity, Nature, 219, 926-927, https://doi.org/10.1038/219926a0, 1968.

Usoskin, I. G., Alanko-Huotari, K., Kovaltsov, G. A., and Mursula, K.: Heliospheric modulation of cosmic rays: Monthly reconstruction for 1951-2004, J. Geophys. Res.-Space, 110, A12108, https://doi.org/10.1029/2005JA011250, 2005. 
Wulf, T.: Über den Ursprung der in der Atmosphäre vorhandenen $\gamma$-Strahlung, Phys. Z., 10, 997-1003, 1909.

Wulf, T.: Beobachtungen über Strahlung hoher Durchdringungsfähigkeit auf dem Eiffelturm, Phys. Z., 11, 811-813, 1910.
Zreda, M., Shuttleworth, W. J., Zeng, X., Zweck, C., Desilets, D., Franz, T., and Rosolem, R.: COSMOS: the COsmic-ray Soil Moisture Observing System, Hydrol. Earth Syst. Sci., 16, 40794099, https://doi.org/10.5194/hess-16-4079-2012, 2012. 